\title{
Gender disparities in access to care for time-sensitive conditions during COVID-19 pandemic in Chile
}

\author{
Jorge Pacheco ${ }^{1}$, Francisca Crispi ${ }^{2}$, Tania Alfaro ${ }^{2}$, María Soledad Martínez ${ }^{2}$ and Cristóbal Cuadrado ${ }^{2,3^{*}}$ (D)
}

\begin{abstract}
Background: During the COVID-19 pandemic, reductions in healthcare utilization are reported in different contexts. Nevertheless, studies have not explored specifically gender disparities in access to healthcare in the context of COVID-19.

Methods: To evaluate gender disparities in access to medical in Chile we conducted an interrupted time series analysis using segmented regression. The outcome variable was the number of weekly confirmed cases of a set of oncologic and cardiovascular time-sensitive conditions at a national level. The series contained data from weeks 1 to 39 for 2017 to 2020. The intervention period started at week 12. We selected this period because preventive interventions, such as school closures or teleworking, were implemented at this point. We estimated the level effect using a dummy variable indicating the intervention period and slope effect using a continuous variable from weeks 12 to 39. To test heterogeneity by gender and age group, we conducted a stratified analysis.

Results: We observed a sizable reduction in access to care with a slowly recovery for oncologic (level effect 0.323; 95\% Cl 0.291-0.359; slope effect 1.022; 95\% Cl 1.016-1.028) and cardiovascular diseases (level effect 0.586; 95\% Cl 0.564-0.609; slope effect 1.009; $95 \% \mathrm{Cl} 1.007-1.011)$. Greater reduction occurred in women compared to men, particularly marked on myocardial infarction (level effect $0.595 ; 95 \% \mathrm{Cl} 0.566-0.627$ versus $0.532 ; 95 \% \mathrm{Cl} 0.502-0.564$ ) and colorectal cancer (level effect 0.295; 95\% Cl 0.248-0.35 versus 0.19; 95\% Cl 0.159-0.228). Compared to men, a greater absolute reduction was observed in women for oncologic diseases, excluding sex-specific cancer, (1352; 95\% Cl 743-1961) and cardiovascular diseases (1268; 95\% Cl 946-1590).
\end{abstract}

Conclusion: We confirmed a large drop in new diagnoses for time-sensitive conditions during the COVID-19 pandemic in Chile. This reduction was greater for women. Our findings should alert policy-makers about the urgent need to integrate a gender perspective into the pandemic response.

Keywords: Gender, Pandemics, Health services accessibility

\footnotetext{
* Correspondence: c.cuadrado@york.ac.uk

EEscuela de Salud Pública, Universidad de Chile, Independencia 939,

Independencia, 8380453 Santiago de Chile, Chile

${ }^{3}$ Centre for Health Economics, University of York, York, UK

Full list of author information is available at the end of the article
}

(c) The Author(s). 2021 Open Access This article is licensed under a Creative Commons Attribution 4.0 International License, which permits use, sharing, adaptation, distribution and reproduction in any medium or format, as long as you give appropriate credit to the original author(s) and the source, provide a link to the Creative Commons licence, and indicate if changes were made. The images or other third party material in this article are included in the article's Creative Commons licence, unless indicated otherwise in a credit line to the material. If material is not included in the article's Creative Commons licence and your intended use is not permitted by statutory regulation or exceeds the permitted use, you will need to obtain permission directly from the copyright holder. To view a copy of this licence, visit http://creativecommons.org/licenses/by/4.0/ The Creative Commons Public Domain Dedication waiver (http://creativecommons.org/publicdomain/zero/1.0/) applies to the data made available in this article, unless otherwise stated in a credit line to the data. 


\section{Background}

The COVID-19 pandemic reduced the utilization of health care services, similarly to the phenomena reported in previous epidemic outbreaks, like SARS [1], MERS [2], and Ebola [3]. In the current pandemic, studies have shown a decrease in the frequency of different interventions like surgeries (electives or not) and hospital admissions, including specific time-sensitive conditions, such as acute coronary syndrome $[4,5]$, myocardial infarctions $[6$, 7], stroke [8-11] and cancer [12-17].

Although it has been largely studied that gender impacts access to healthcare [18-20], gender differences in access to healthcare have been scarcely examined during the COVID-19 pandemic. While most studies have not explored heterogeneity by gender [4, 9-15], some studies that examine differences between men and women on acute coronary syndrome [5, 6] and stroke [8] have not found relevant disparities. Only one study was done in Latin America and did not explore gender differences [11]. To the best of our knowledge, a single research explored access differences in cancer care by gender during the pandemic. The authors did not identify any relevant differences, although the more considerable decrease was for breast cancer [17].

Gender has been proposed as a structural determinant of health, as gender norms shape social stratification, health-related exposures and behaviors, healthcare access, health systems, and health research [21]. Nevertheless, the response to outbreaks has been usually devoid of a gender perspective, limiting the effectiveness of the public health response [22, 23].

Gender norms and stratification influence social and economic outcomes, which in turn could impact access to health care [24]. First, evidence has demonstrated that school closure and mandatory confinement have increased caregiving responsibilities in families, which traditionally fall on women, producing significant disruption in their daily lives compared with men [25]. Second, as there is a general reduction in the availability of health services, gender bias that usually affects access for women, especially to cardiovascular diseases, may increase [26]. Finally, during the pandemic, employment was impacted, and many people suffered income reduction. As women are overrepresented in informal jobs, they experienced higher unemployment rates and a more significant reduction in working hours and salaries compared with men during the pandemic in different contexts [27, 28]. Also, COVID19 has increased levels of gender violence, and reproductive health is usually not prioritized during emergencies [24], potentially reducing access to relevant diagnostic services such as smear tests for cervical cancer. Furthermore, it is important to consider in this framework the intersections that each of these areas has with other conditions such as age, socioeconomic level, ethnic background, migration status, and others, which may modify their implications [29].

This study aims to evaluate disparities between men and women in access to medical care in Chile during the COVID-19 pandemic. We focus on severe and timesensitive group conditions (cardiovascular diseases and cancer) with guaranteed access in the context of the Chilean health system. As observed in other countries, we hypothesized a large drop in both group conditions diagnosis, but with a more significant decrease in women.

\section{Methods \\ Study setting}

In 2005 Chile implemented a Health Reform which included the National Explicit Health Guarantees Regime ("AUGE", nowadays "GES" - explicit guarantees in health-), a set of guarantees aimed to ensure access to timely (opportunity guarantee), affordable, and quality services for people of both insurance systems predominant in Chile (public, National Health Fund - FONASA -, and private, ISAPRES), for 56 health conditions, which have been amplified to 85 nowadays [30]. During the current pandemic, the obligation for FONASA and ISAPRES to comply with the Explicit Guarantee of opportunity established for the health problems was suspended for up to 1 month since the 8th of April, except for severe conditions included in this study such as acute myocardial infarction, stroke, and cancers.

Before the onset of the pandemic, Chilean women used more healthcare services than men. They declared a worse self-perception of their health status and a greater number of healthcare needs [31]. In relation to health conditions included in GES, women have a larger waiting time than men, especially in the age group between 35 to 49 years [20]. For acute myocardial infarction, women in Chile have higher in-hospital mortality and a lower probability of receiving treatment of proven clinical efficacy compared to men [32].

\section{Variables conceptualization Gender}

Sex and gender are highly entangled, and therefore is difficult to separate them for analysis [33]. In this study, we state that the measured differences in access to healthcare by sex are explained mainly by gender norms. First, because the role of gender in access to healthcare has been previously studied as a relevant factor [18-20]. Second, because it seems less plausible that the variations between females and males in the utilization before and after the pandemic are due to biological characteristics. Therefore, and following other authors who choose the term gender to account for social and structural factors [33], hereafter the manuscript refers to "gender" for the studied categories of women and men. 


\section{Health care utilization}

According to Levesque's model of health care accessibility [34], we conceptualize health care utilization as the result of a dynamic interplay between individuals and services. In this model, access is defined as an opportunity to reach and obtain appropriate health care services in situations of perceived need for care. Five dimensions of health services explain accessibility: approachability, acceptability, availability and accommodation, affordability, and appropriateness. Each of these dimensions is related to an individual ability to generate access: the ability to perceive, ability to seek, ability to pay, and ability to engage. Health care access barriers (or facilitators) can appear in each dimension and occur in a cumulative manner. During the pandemic, emerging barriers decreased accessibility to health care services, affecting individuals (e.g. decrease of acceptability due to fear of contagion) and services (e. g. decrease of availability due to human resources diversion) reducing health care utilization. Such barriers can be different in type and intensity based on gender-roles.

\section{Data sources}

We obtained data from the National Health Fund (Fondo Nacional de Salud - FONASA) which finances all public hospitals in Chile and provides health coverage to nearly 15 million inhabitants $(75 \%$ of the Chilean population). We selected a set of nine time-sensitive conditions included in the National Explicit Health Guarantees Regime ("AUGE"): two acute cardiovascular diseases (stroke and myocardial infarction) and seven cancers (gastric cancer, colorectal cancer, lymphoma, leukemia, cervical cancer, breast cancer, and testis cancer). We selected both group conditions because they encompass the two major causes of death in Chile. Additionally, delayed care for time-sensitive conditions, such as major cardiovascular events and cancer, can lead to an increased risk of long-term disability and premature death. Also, the demand for acute cardiovascular diseases is inelastic so short-term variations indicate severe disruptions in health services utilization [35].

The attending physician registers every public-insured patient with a medical diagnosis of these conditions as a confirmed case. National clinical guidelines standardize the diagnostic process for each disease, reducing practice variation and improving reporting quality. A confirmed case report is mandatory by law for healthcare providers. A description of case definitions included in the $\mathrm{Na}$ tional Clinical Guidelines is available in the Supplementary File 1 (Table S1).

\section{Analysis}

We conducted an interrupted time-series analysis using a segmented regression [36]. Due to the count nature of the data (number of cases diagnosed per week), we fitted generalized linear models with a Negative Binomial distribution. The outcome variable was the number of confirmed cases for the following diseases: stroke (includes transient ischemic attack), myocardial infarction, all cardiovascular diseases (stroke plus myocardial infarction), gastric cancer, colorectal cancer, lymphoma, leukemia, cervical cancer (includes dysplasia), breast cancer, testicular cancer, and all cancers.

The series contained data from epidemiological weeks 1 (December 30th to January 5th) to 39 (September 21th to 27th) for the years 2017 to 2020 (156 weeks). The intervention period started at week 12 (March 16th to 22th). We selected this period because most of the public health interventions implemented during the pandemic, including school closures and remote working recommendations, started at this point (March 15th). Also, in that period started a process of cessation of elective surgeries and centralization of acute beds by the Ministry of Health. Interventions and dates details are available in the Supplementary File 1 (Table S2).

The model was defined as:

$$
\begin{aligned}
\log \left(Y_{d t}\right)= & \log \left(P_{d t}\right)+\beta_{0}+\beta_{1} \text { time }+\beta_{2} \text { intervention } \\
& +\beta_{3} \text { intervention } * \text { tfter }+\beta_{4} \text { age }+Z_{d t}+\varepsilon
\end{aligned}
$$

With $Y_{d t}$ the number of confirmed cases of disease $d$ in week $t, P_{d t}$ the population (number) of public health beneficiaries by age-group, $\beta_{1}$ is the time elapsed since the start of the study (in weeks), $\beta_{2}$ is a dummy variable indicating the intervention period (coded 1$), \beta_{3}$ is the time elapsed since the beginning of the intervention (in weeks), $\beta_{4}$ adjust for the effect of age (20 to 29 years, 30 to 39 years, 40 to 49 years, 50 to 59 years, 60 to 69 years, 70 to 79 years, 80 years, and more), $Z_{d t}$ a vector of adjustment co-variable for weekly and yearly seasonal fixed effect terms and $\varepsilon$ is an error term.

To test heterogeneity, we did stratified analysis by gender and gender-age. As a sensitivity analysis, we fitted unadjusted and adjusted models for all cancers, after excluding sex-specific cancers (breast cancer, cervical cancer, and testicular).

We reported the mean and standard deviation for descriptive analysis and incidence rate ratios (IRR) and absolute effects (counts) with 95\% confidence intervals for regressions models. We used STATA 16.0 for analyses.

\section{Results}

We analyzed a total of 156 weeks with 327,477 cardiovascular events $(83,034$ strokes and 244,443 myocardial infarction) and 137,700 cancer diagnoses (23,135 gastric cancers, 24,579 colorectal cancers, 5,290 lymphomas, 2535 leukemia, 42,143 cervical cancers, 37,443 breast 


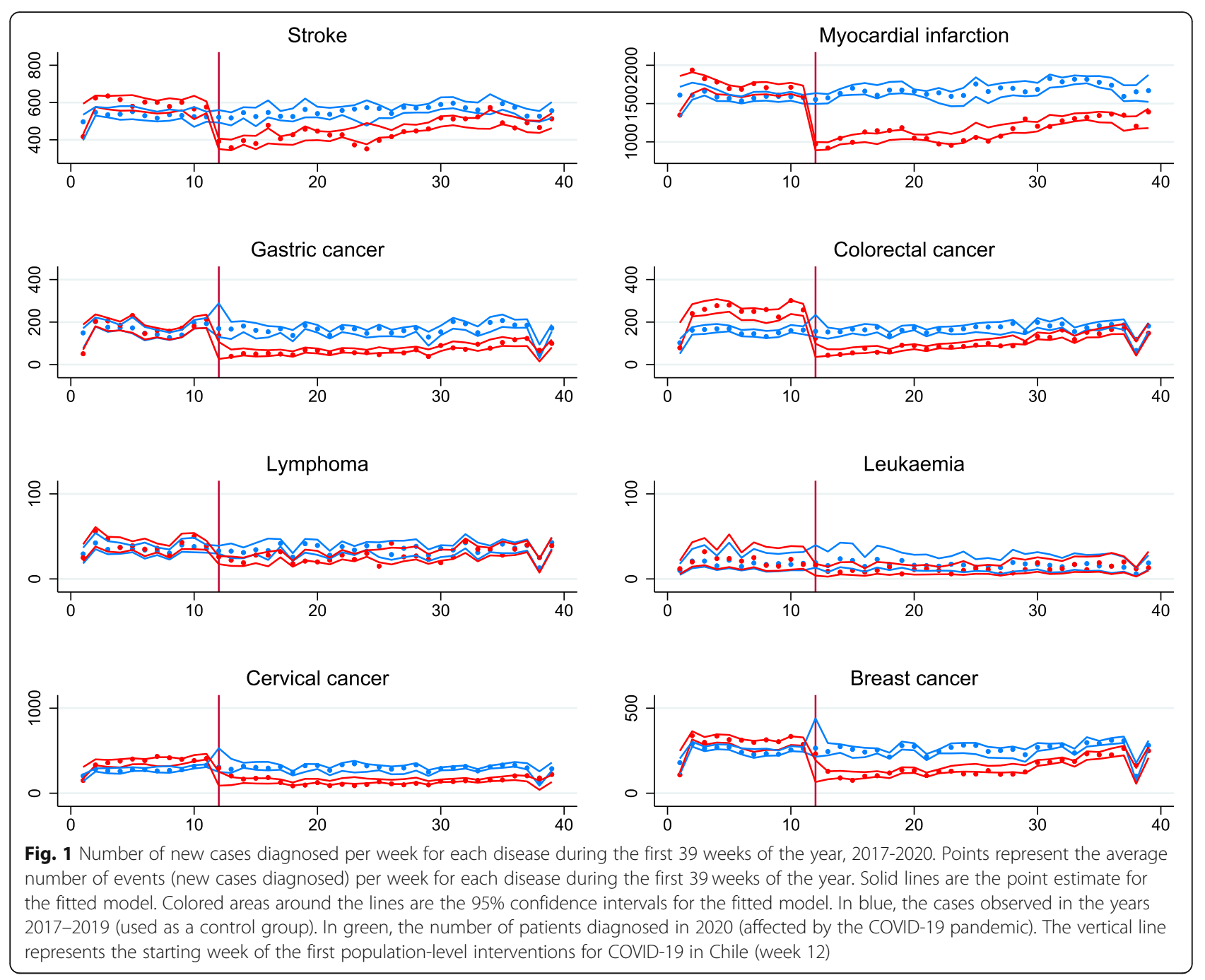

cancers, and 2,575 testicular cancers) during the study period (Table S3, Supplementary File 1).

Compared to previous years (2017-2019), after week 12 (March 16, 2020) an immediate downward trend in the number of events was confirmed for all diseases (Fig. 1). In the oncologic diseases group, a smaller decrease occurred for lymphoma and leukemia (Fig. 1). In the cardiovascular diseases group, we observe more substantial reductions for myocardial infarction compared to stroke. Previous to the observed downward, trends were parallel for all studied diseases. The drop observed at week 38 is related to the national holiday. When analyzed by gender, women showed a greater impact on their access compared with men for both diseases groups during the study period (Fig. 2).

In our model, we confirmed a larger immediate reduction (level effect) for cancer conditions $(0.323 ; 95 \% \mathrm{CI}$ 0.291-0.359) compared to the cardiovascular events $(0.586$; $95 \%$ CI $0.564-0,609)$. In contrast, the post intervention slope was larger for cancer conditions (1.022;
95\% CI 1.016-1.028) than cardiovascular events (1.009; 95\% CI 1.007-1.011) (Table 1). Among cancer conditions, a greater immediate reduction was observed in colorectal cancer $(0.229 ; 95 \%$ CI $0.199-0.265)$, gastric cancer $(0.306 ; 95 \%$ CI 0.253-0.371), cervical cancer (0.335; 95\% CI $0.287-0.392)$ and breast cancer (0.336; 95\% CI 0.293-0.385). A greater post intervention slope was observed in colorectal cancer $(1.036$ 95\% CI 1.028 1.043), breast cancer (1.028 95\% CI 1.021-1.036) and gastric cancer (1.022 95\% 1.011-1.032). This suggest a rapid recovery trend for this diagnosis after the initial abrupt reduction for this conditions. In the cardiovascular group, the most affected condition was myocardial infarction (0.564 95\% CI 0.539-0.589) with similar post intervention trends. (Table 1).

A differential impact, with larger effects on women than men, was observed across cardiovascular and oncological diseases. For the former, a 6.8\% $(0.62195 \% \mathrm{CI}$ $0.593-0.65$ in men and $0.55395 \%$ CI $0.527-0.579$ in women) additional immediate reduction in access for 


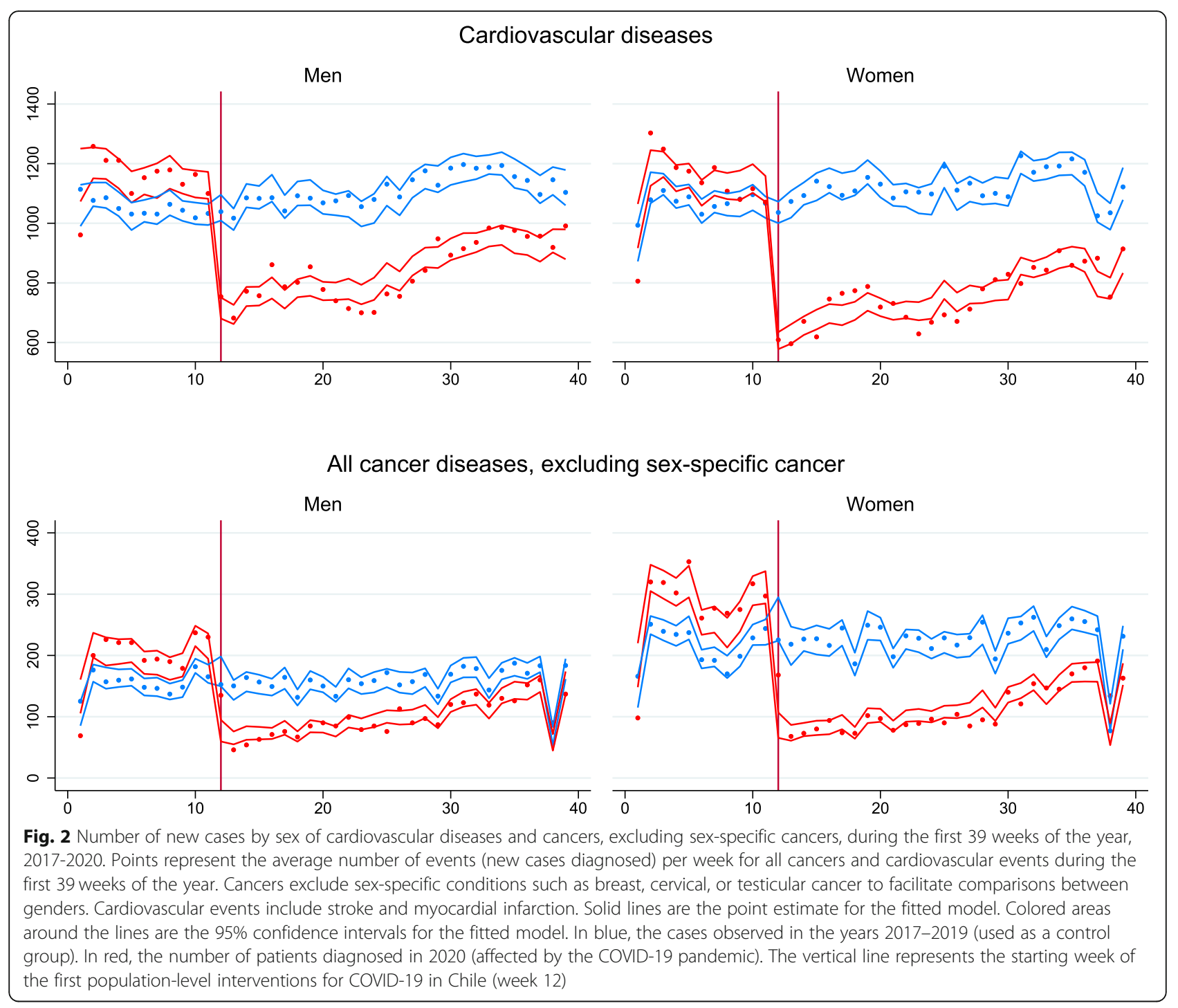

cardiovascular events in women compared with men was evident. For the latter, a further non-significant 5.2\% immediate reduction $(0.364 ; 95 \%$ CI $0.315-0.408$ in men and $0.31295 \%$ CI $0.279-0.35$ ) in access to newly diagnosed cancers among females compared with males was observed in the pandemic period. In the sensitivity analysis, differences between sexes in the cancer group increased after excluding sex-specific cancers such as breast, cervical, and testicular cancers. In this analysis, a bigger impact on access was confirmed among women (0.351; IC 95\% 0.302-0.408 in men and 0.254; IC95\% $0.218-0.296$ in men). Differences in post-intervention trends were similar in both groups. (Table 1).

When analyzed by specific cardiovascular diseases, a greater immediate decrease in women than men took place for myocardial infarction $(0.697$; $95 \%$ CI $0.649-$ 0.75 in men and $0.53295 \%$ CI $0.502-0.564$ in women). When analyzed by specific oncologic diseases, a greater immediate decrease in women than men occurred for colorectal cancer $(0.295 ; 95 \%$ CI $0.248-0.35$ in men and 0.19; $95 \%$ CI $0.159-0.228$ in women). Also, a greater immediate reduction on cervical cancer $(0-33595 \%$ CI 0287-0.392) and breast cancer (0.336 95\% CI 0.293$0.385)$ compared to testicular cancer $(0.469 ; 95 \% \mathrm{CI}$ 0.339-0.649) was observed (Table 1). Post intervention trends were similar for all specific cardiovascular and oncologic diseases.

To make sense of these findings, we also present absolute effects sizes. A greater absolute effect in access for women compared to men occurred in almost all 
Table 1 Incidence Rate Ratio for weekly confirmed cases during the pandemic period (week 12-39)

\begin{tabular}{|c|c|c|c|c|c|c|}
\hline & Both sexes & & Men & & Women & \\
\hline & Level effect & Slope effect & Level effect & Slope effect & Level effect & Slope effect \\
\hline All cardiovascular diseases & $\begin{array}{l}0.586(0.564- \\
0.609)\end{array}$ & $\begin{array}{l}1.009(1.007- \\
1.011)\end{array}$ & $\begin{array}{l}0.621(0.593- \\
0.65)\end{array}$ & $\begin{array}{l}1.008(1.005- \\
1.01)\end{array}$ & $\begin{array}{l}0.553(0.527- \\
0.579)\end{array}$ & $\begin{array}{l}1.01(1.008- \\
1.012)\end{array}$ \\
\hline $\begin{array}{l}\text { Stroke (includes transient ischemic } \\
\text { attack) }\end{array}$ & $\begin{array}{l}0.653(0.617- \\
0.691)\end{array}$ & $\begin{array}{l}1.008(1.006- \\
1.011)\end{array}$ & $\begin{array}{l}0.6970 .649- \\
0.75)\end{array}$ & $\begin{array}{l}1.008(1.005- \\
1.012)\end{array}$ & $\begin{array}{l}0.613(0.571- \\
0.658)\end{array}$ & $\begin{array}{l}1.008(1.005- \\
1.012)\end{array}$ \\
\hline Myocardial infarction & $\begin{array}{l}0.563(0.539- \\
0.589)\end{array}$ & $\begin{array}{l}1.009(1.007- \\
1.011)\end{array}$ & $\begin{array}{l}0.595(0.566- \\
0.627)\end{array}$ & $\begin{array}{l}1.007(1.005- \\
1.01)\end{array}$ & $\begin{array}{l}0.532(0.502- \\
0.564)\end{array}$ & $\begin{array}{l}1.011(1.008- \\
1.014)\end{array}$ \\
\hline All cancer & $\begin{array}{l}0.323(0.291- \\
0.359)\end{array}$ & $\begin{array}{l}1.022(1.016- \\
1.028)\end{array}$ & $\begin{array}{l}0.364(0.315- \\
0.42)\end{array}$ & $\begin{array}{l}1.024(1.017- \\
1.031)\end{array}$ & $\begin{array}{l}0.312(0.279- \\
0.35)\end{array}$ & $\begin{array}{l}1.021(1.015- \\
1.028)\end{array}$ \\
\hline $\begin{array}{l}\text { All cancer (excluding sex specific } \\
\text { cancer) }\end{array}$ & $\begin{array}{l}0.293(0.258- \\
0.334)\end{array}$ & $\begin{array}{l}1.028(1.021- \\
1.035)\end{array}$ & $\begin{array}{l}0.351(0.302- \\
0.408)\end{array}$ & $\begin{array}{l}1.025(1.017- \\
1.033)\end{array}$ & $\begin{array}{l}0.254(0.218- \\
0.296)\end{array}$ & $\begin{array}{l}1.03(1.022- \\
1.038)\end{array}$ \\
\hline Gastric cancer & $\begin{array}{l}0.306(0.253- \\
0.371)\end{array}$ & $\begin{array}{l}1.022(1.011- \\
1.032)\end{array}$ & $\begin{array}{l}0.338(0.265- \\
0.431)\end{array}$ & $\begin{array}{l}1.021(1.008- \\
1.035)\end{array}$ & $\begin{array}{l}0.228(0.231- \\
0.36)\end{array}$ & $\begin{array}{l}1.021(1.009- \\
1.033)\end{array}$ \\
\hline Colorectal cancer & $\begin{array}{l}0.229(0.199- \\
0.265)\end{array}$ & $\begin{array}{l}1.036(1.028- \\
1.043)\end{array}$ & $\begin{array}{l}0.295(0.248- \\
0.35)\end{array}$ & $\begin{array}{l}1.032(1.023- \\
1.041)\end{array}$ & $\begin{array}{l}0.19(0.159- \\
0.228)\end{array}$ & $\begin{array}{l}1.038(1.029- \\
1.048)\end{array}$ \\
\hline Lymphoma & $\begin{array}{l}0.569(0.467- \\
0.693)\end{array}$ & $\begin{array}{l}1.017(1.007- \\
1.028)\end{array}$ & $\begin{array}{l}0.643(0.49- \\
0.844)\end{array}$ & $\begin{array}{l}1.009(0.996- \\
1.022)\end{array}$ & $\begin{array}{l}0.497(0.378- \\
0.655)\end{array}$ & $\begin{array}{l}1.025(1.01- \\
1.039)\end{array}$ \\
\hline Leukaemia & $\begin{array}{l}0.388(0.286- \\
0.526)\end{array}$ & $\begin{array}{l}1.031(1.015- \\
1.047)\end{array}$ & $\begin{array}{l}0.383(0.251- \\
0.586)\end{array}$ & $\begin{array}{l}1.034(1.011- \\
1.058)\end{array}$ & $\begin{array}{l}0.392(0.259- \\
0.594)\end{array}$ & $\begin{array}{l}1.027(1.006- \\
1.05)\end{array}$ \\
\hline Cervical cancer (includes dysplasia) & - & - & - & - & $\begin{array}{l}0.335(0.287- \\
0.392)\end{array}$ & $\begin{array}{l}1.007(0.998- \\
1.016)\end{array}$ \\
\hline Breast cancer & - & - & - & - & $\begin{array}{l}0.336(0.293- \\
0.385)\end{array}$ & $\begin{array}{l}1.028(1.021- \\
1.036)\end{array}$ \\
\hline Testicular cancer & - & - & $\begin{array}{l}0.469 \text { (0.339- } \\
0.649)\end{array}$ & $\begin{array}{l}1.013(0.997- \\
1.029)\end{array}$ & - & - \\
\hline
\end{tabular}

${ }^{a}$ Interrupted time series analysis by sex adjusted by age, population size, and seasonality (week and year). The model includes level and slope effect terms. Complete models are available in Supplemental material (Table S3-S5)

conditions (Table 2). An excess impact in women compared to men was observed for oncologic $(9,140 ; 95 \%$ CI $4,619-13,661)$ and cardiovascular diseases $(1,268 ; 95 \% \mathrm{CI}$ $946-1,590)$ during the 28 weeks of the pandemic included in the study period. In the sensitivity analysis, differences between genders persisted but were smaller (1,352; $95 \%$ CI $743-1,916)$. When analyzed by specific diseases, we found sizable differences in access for women compared to men for myocardial infarction $(729$ 95\% CI 631-930), colorectal cancer (844 95\% CI 2881401), gastric cancer (562; 95\% CI 362-762) and stroke (538 95\% CI 250-624).

In our final analysis, we estimated relative and absolute effects across gender and age groups for cardiovascular

Table 2 Absolute reduction in confirmed cases during the pandemic period (week 12-39)

\begin{tabular}{|c|c|c|c|}
\hline & $\begin{array}{l}\text { Men } \\
\text { Count }(95 \% \mathrm{CI})\end{array}$ & $\begin{array}{l}\text { Women } \\
\text { Count }(95 \% \mathrm{Cl})\end{array}$ & $\begin{array}{l}\text { Excess impact on woman } \\
\text { Count }(95 \% \mathrm{CI})\end{array}$ \\
\hline All cardiovascular diseases & $9,047(6,845-11,248)$ & $10,315(7,791-12,838)$ & $1,268(946-1,590)$ \\
\hline Stroke (includes transient ischemic attack) & $1,557(798-2,214)$ & $2,286(1,428-3,144)$ & $729(631-930)$ \\
\hline Myocardial infarction & $7,497(5,702-8,906)$ & $8,035(5,952-9,529)$ & $538(250-624)$ \\
\hline All cancer & $2,056(611-3,161)$ & $11,196(5,229-17,163)$ & $9,140(4,619-13,661)$ \\
\hline All cancer (excluding sex specific cancer) & $1,863(564-3,161)$ & $3,215(1,307-5,122)$ & $1,352(743-1,961)$ \\
\hline Gastric cancer & $828(44-1,612)$ & $1,390(406-2,374)$ & $562(362-762)$ \\
\hline Colorectal cancer & $896(348-1,444)$ & $1,740(636-2,844)$ & $844(288-1,401)$ \\
\hline Lymphoma & $128(-25-281)$ & $111(-36-258)$ & $17(11-23)$ \\
\hline Leukemia & $10(-20-40)$ & $15(-44-13)$ & $-5(-4--7)$ \\
\hline Cervical cancer (includes dysplasia) & .. & $5,185(2,522-7,848)$ &.. \\
\hline Breast cancer & .. & $2,931(784-5,078)$ & .. \\
\hline Testicular cancer & $202(-25-430)$ & .. & .. \\
\hline
\end{tabular}


diseases and oncologic diseases, excluding sex-specific cancer (Table S4). For cardiovascular diseases, we only observed a significant immediate decrease for the 20 to 29 years' group. A larger absolute difference for women compared to men was observed in the older groups (527 95\% CI $485-569$ in the 70 to 79 years' group and 668 95\% CI 472-614 in the 80 years and older group). For oncologic diseases, a larger immediate decrease was evident for women in all ages groups, and the greater absolute difference was observed among middle-aged and older women ( $42695 \%$ CI $175-676$ in 50 to 59 years' group and $39595 \%$ CI $364-427$ in 60 to 69 years group).

\section{Discussion}

Our analysis confirmed a large drop in the access to medical diagnosis for cardiovascular and oncologic conditions in Chile during COVID-19 pandemic as previous studies have shown [4-15], This decrease was more significant for oncologic than cardiovascular diseases. Also, we confirmed our hypothesis of sizable gender disparities in the impact of the pandemic on access to medical care. A large group of time-sensitive conditions was affected by this differential effect, even though healthcare access for these conditions is guaranteed by law in Chile. This finding is worrisome because delaying care for these severe conditions can lead to long-term disability and - eventually - premature mortality.

Because cardiovascular diseases and cancers have different etiological mechanisms, it is highly implausible to explain this finding through biological mechanisms. While a stroke and myocardial infarction could increase after COVID-19 infection [37, 38], a reduction in the number of diagnosed cardiovascular events is probably explained by decreased access to healthcare. If men are more prone to COVID-19 [39], this could explain, at least partially, that the decline in stroke and myocardial infarction in males could be smaller compared with women. Although, this explanation cannot be given in cancer because these diseases do not share the same causes and acute changes in cancer incidence are unlikely to be attributable to COVID-19 infection. In this setting, a reduced number of newly diagnosed cancers, particularly among women, is a clear marker of reduced access and unmet needs.

Gender norms and hierarchies could explain this wide effect better. During the pandemic, women faced more health care barriers than men. Income decrease due to work hours reduction [27] and higher unemployment [28] reduced women's ability to pay for health care. Also, interventions to reduce COVID-19 transmission, such as school closures, increased the care burden in families reducing women's time availability to seek care [25]. This could explain the greater differential effect observed on diseases that require scheduled appointments for testing (e.g., colorectal, cervical, gastric, and breast cancer).

From a health services perspective, the diversion of resources (health personnel, hospital beds, among others) to cope with the pandemic reduced provider's availability for cancer and cardiovascular care. Previous to the pandemic, women waited more time than men to access care for these health conditions [20]. For acute myocardial infarction, the treatment of women was proven suboptimal compared to men [32]. These gender biases could be aggravated in the context of health services scarcity, differentially affecting the ability to reach and use health care services in women [21].

Finally, fear of SARS-CoV-2 contagion in medical settings could reduce the acceptability of health services, decreasing the user's ability to seek care. The reduction of health services utilization showed a rapid onset starting when the first control measures were established. This sudden decrease preceded the stay-at-home mandates (March 26) and lockdowns (May 13). Also, it preceded the period of the highest incidence of cases (MayJune). This pattern could be explained by user fear triggered by extensive media coverage about death overseas and the uncertainty of a new infectious disease during the first weeks of the pandemic. A Chilean survey evidenced that this fear was more frequent in women than in men [40]. It is unclear why women suffered more fear but this could partly explain immediate differences in access to health care.

Women's health access disruption has been observed for other conditions. A recent systematic review concluded that maternal and fetal outcomes worsened during the COVID-19 pandemic with an increase in maternal deaths, stillbirth, ruptured ectopic pregnancies, and maternal depression [41]. Similar disruptions were observed for contraception and safe abortion services [24]. According to these findings, an urgent call to protect sexual and reproductive care and to include a gender perspective in the pandemic response was raised by multiple humanitarian organizations [42].

As strengths, this is the first study from Latin America that explores access by gender to medical diagnosis during the COVID-19 pandemic. To test our hypothesis, we used a rich, comprehensive, and reliable national database where cases were defined based on standardized diagnostic processes. We select a variety of severe timesensitive conditions to avoid generalization based on anecdotal evidence. Moreover, we tested different models, maintaining our conclusions unchanged.

This study has several limitations. First, we use administrative data, which might be subject to underreporting during the pandemic. Nevertheless, confirmed case reports have been mandatory for healthcare providers since 2004. Moreover, they are used for health claim 
payments in the Chilean health system, therefore making it less likely that reduced reporting could explain the observed effect. Second, due to the data codification, this study only considers two categories for sex and gender (female and male). This dichotomy excludes a spectrum of gender identities and the intersex population [21]. Future studies must explore differential effects on health care accessibility during pandemics for broader gender classification. Third, we cannot rule out residual confounding in the context of observational data. Nevertheless, due to the characteristic of the exposure of interest (the pandemic) is unlikely that better data could be obtained using alternative sources or study designs. We controlled confirmed cases by population and age in our models and included seasonal adjustments by week and year to control for unobserved time-specific confounding factors. The use of previous year trends as a control for the same observational units allows adjustment for confounding, but since no parallel control group was available adjustment for other time-variant effects concomitants to the pandemic was not feasible.

\section{Conclusion}

In our study, we confirmed a large drop in the medical diagnosis for time-sensitive conditions during the COVID-19 pandemic in Chile. Additionally, we demonstrate that women were far more affected compared to men. This differential effect by gender was observed for a broad group of time-sensitive conditions. As researchers have posed [22, 23], our findings should alert policy-makers about the urgent need to integrate a gender perspective into outbreak response. If school closure has a role in the observed differential effect, increasing the number of health care services will not be enough to shorten these disparities between genders. Services provision should be reachable, especially for women who are raising children or have other caregiver responsibilities and reduce economic barriers. Also, health professionals should be aware of this situation and encouraged through clinical guidelines to reduce current gender bias in their clinical practice.

Future research must evaluate the consequences of access reductions on disability and premature death. The observed effect occurred in a set of severe time-sensitive conditions where care delays could worsen prognosis. Additionally, we need to know the causes, which could be informed through surveys and innovative ways to provide care for these diseases during the actual pandemic.

\section{Abbreviations}

AUGE: Acceso Universal a Garantías Explícitas (National Explicit Health Guarantees Regime); COVID-19: Coronavirus disease 2019; FONASA: Fondo Nacional de Salud (Public insurer); IRR: Incidence Rate Ratio; ISAP RES: Instituciones de Salud Previsional (Private insurers); MERS: Middle East respiratory syndrome; SARS: Severe acute respiratory syndrome

\section{Supplementary Information}

The online version contains supplementary material available at https://doi. org/10.1186/s12889-021-11838-x.

\section{Additional file 1.}

Acknowledgments

The authors thank FONASA for providing databases for this research and Prof. Sandra Flores for suggestions to improve the methods applied on early versions of this manuscript.

\section{Authors' contributions}

JP did literature research, collected data, developed the study design, analyzed data and drafted the manuscript. FC did literature research, design figures, interpreted data and drafted the manuscript. TA did literature research, analyzed data, interpreted data and drafted the manuscript. MSM interpreted data and critically revised the manuscript. CC developed the study design, interpreted data, design graphs, and drafted the manuscript. All authors read and approved the final manuscript.

\section{Funding}

This work was supported by the National Agency for Research and Development (ANID), Scholarship program, DOCTORADO BECAS CHILE 2020-21200241 and COVID research fund ANID-COVID0960. The funding bodies played no role in the design of the study and collection, analysis, and interpretation of data and in writing the manuscript.

\section{Availability of data and materials}

The datasets supporting the conclusions of this article are available in the GitHub repository: https://github.com/CoV-IMPACT-C/gender-impact-accesscovid

\section{Declarations}

Ethics approval and consent to participate

Since this study used secondary data from publicly available sources collected by the Ministry of Health, which are registered anonymously, we did not require institutional review board approval.

Consent for publication

Not applicable.

\section{Competing interests}

The authors declare that they have no competing interests.

\section{Author details}

1 Departamento de Salud Pública, Universidad de Concepción, Víctor Lamas 1290 Casilla 160-C, 4070386 Concepción, Chile. ²Escuela de Salud Pública, Universidad de Chile, Independencia 939, Independencia, 8380453 Santiago de Chile, Chile. ${ }^{3}$ Centre for Health Economics, University of York, York, UK.

Received: 6 April 2021 Accepted: 22 September 2021

Published online: 19 October 2021

\section{References}

1. Chang HJ, Huang N, Lee CH, Hsu YJ, Hsieh CJ, Chou YJ. The impact of the SARS epidemic on the utilization of medical services: SARS and the fear of SARS. Am J Public Health. 2004;94(4):562-4. https://doi.org/10.2105/ajph. 94.4.562.

2. Lee SY, Khang YH, Lim HK. Impact of the 2015 Middle East respiratory syndrome outbreak on emergency care utilization and mortality in South Korea. Yonsei Med J. 2019;60(8):796-803. https://doi.org/10.3349/ymj.2019. 60.8.796.

3. Brolin Ribacke KJ, Saulnier DD, Eriksson A, von Schreeb J. Effects of the West Africa Ebola virus disease on health-care utilization - a systematic review. Front Public Health. 2016;4. https://doi.org/10.3389/fpubh.2016.00222.

4. De Filippo O, D'Ascenzo F, Angelini F, Bocchino PP, Conrotto F, Saglietto A, et al. Reduced rate of hospital admissions for ACS during Covid-19 outbreak in northern Italy. N Engl J Med. 2020:383(1):88-9. https://doi.org/10.1056/ NEJMc2009166. 
5. Mafham MM, Spata E, Goldacre R, Gair D, Curnow P, Bray M, et al. COVID-19 pandemic and admission rates for and management of acute coronary syndromes in England. Lancet. 2020. https://doi.org/10.1016/50140-6736(2 0)31356-8.

6. Solomon MD, McNulty EJ, Rana JS, Leong TK, Lee C, Sung SH, et al. The Covid-19 pandemic and the incidence of acute myocardial infarction. N Engl J Med. 2020;383(7):691-3. https://doi.org/10.1056/NEJMc2015630.

7. Baum A, Schwartz MD. Admissions to veterans affairs hospitals for emergency conditions during the COVID-19 pandemic. JAMA. 2020;324(1): 96-9. https://doi.org/10.1001/jama.2020.9972.

8. Rudilosso S, Laredo C, Vera V, Vargas M, Renú A, Llull L, et al. Acute stroke care is at risk in the era of COVID-19: experience at a comprehensive stroke Center in Barcelona. Stroke. 2020;51(7):1991-5. https://doi.org/10.1161/ STROKEAHA.120.030329.

9. Hoyer C, Ebert A, Huttner HB, Puetz V, Kallmünzer B, Barlinn K, et al. Acute stroke in times of the COVID-19 pandemic: a multicenter study. Stroke. 2020;51(7):2224-7. https://doi.org/10.1161/STROKEAHA.120.030395.

10. Zhao J, Li H, Kung D, Fisher M, Shen Y, Liu R. Impact of the COVID-19 epidemic on stroke care and potential solutions. Stroke. 2020;51(7):19962001. https://doi.org/10.1161/STROKEAHA.120.030225.

11. Diegoli H, Magalhães PSC, Martins SCO, Moro CHC, França PHC, Safanelli J, et al. Decrease in hospital admissions for transient ischemic attack, mild, and moderate stroke during the COVID-19 era. Stroke. 2020;51 (8):2315-21. https://doi.org/10.1161/STROKEAHA.120.030481.

12. Dinmohamed AG, Visser O, Verhoeven RHA, Louwman MWJ, van Nederveen FH, Willems SM, et al. Fewer cancer diagnoses during the COVID-19 epidemic in the Netherlands. Lancet Oncol. 2020;21(6):750-1. https://doi. org/10.1016/S1470-2045(20)30265-5

13. Rutter MD, Brookes M, Lee TJ, Rogers P, Sharp L. Impact of the COVID-19 pandemic on UK endoscopic activity and cancer detection: a National Endoscopy Database Analysis. Gut. 2021;70(3):537-43. https://doi.org/10.113 6/gutjnl-2020-322179.

14. Guven DC, Aktas BY, Aksun MS, Ucgul E, Sahin TK, Yildirim HC, et al. COVID19 pandemic: changes in cancer admissions. BMJ Support Palliat Care. 2020: bmjspcare-2020-002468. https://doi.org/10.1136/bmjspcare-2020-002468.

15. Zadnik V, Mihor A, Tomsic S, Zagar T, Bric N, Lokar K, et al. Impact of COVID19 on cancer diagnosis and management in Slovenia - preliminary results. Radiol Oncol. 2020:54(3):329-34. https://doi.org/10.2478/raon-2020-0048.

16. Filipe MD, van Deukeren D, Kip M, Doeksen A, Pronk A, Verheijen PM, et al. Effect of the COVID-19 pandemic on surgical breast Cancer Care in the Netherlands: a multicenter retrospective cohort study. Clin Breast Cancer. 2020;20(6):454-61. https://doi.org/10.1016/j.clbc.2020.08.002.

17. Kaufman HW, Chen Z, Niles J, Fesko Y. Changes in the number of US patients with newly identified Cancer before and during the coronavirus disease 2019 (COVID-19) pandemic. JAMA Netw Open. 2020;3(8):e2017267. https://doi.org/10.1001/jamanetworkopen.2020.17267.

18. Annandale E, Harvey J, Cavers D, Dixon-Woods M. Gender and access to healthcare in the UK: a critical interpretive synthesis of the literature. Evidence Policy. 2007;3(4):463-86. https:/doi.org/10.1332/174426407782516538.

19. Socías ME, Koehoorn M, Shoveller J. Gender inequalities in access to health care among adults living in British Columbia. Canada Womens Health Issues. 2016;26(1):74-9. https://doi.org/10.1016/j.whi.2015.08.001.

20. Mondschein S, Quinteros M, Yankovic N. Gender bias in the Chilean public health system: do we all wait the same? PLoS One. 2020;15(9):e239445. https://doi.org/10.1371/journal.pone.0239445.

21. Heise L, Greene ME, Opper N, Stavropoulou M, Harper C, Nascimento M, et al. Gender inequality and restrictive gender norms: framing the challenges to health. Lancet. 2019. https://doi.org/10.1016/S0140-6736(19)3 0652-X.

22. Smith J. Overcoming the 'tyranny of the urgent': integrating gender into disease outbreak preparedness and response, Gender \& Development; 2019. https://doi.org/10.1080/13552074.2019.1615288.

23. Wenham C, Smith J, Morgan R, Gender and COVID-19 Working Group. COVID-19: the gendered impacts of the outbreak. Lancet. 2020. https://doi. org/10.1016/S0140-6736(20)30526-2

24. Connor J, Madhavan S, Mokashi M, Amanuel H, Johnson NR, Pace LE, et al. Health risks and outcomes that disproportionately affect women during the Covid-19 pandemic: a review. Soc Sci Med. 2020;266:113364. https://doi. org/10.1016/j.socscimed.2020.113364.

25. Power K. The COVID-19 pandemic has increased the care burden of women and families, Sustainabil Sci Pract Policy, 2020; DOI: https://doi.org/10.1080/1
5487733.2020.1776561, The COVID-19 pandemic has increased the care burden of women and families.

26. Haider A, Bengs S, Luu J, Osto E, Siller-Matula JM, Muka T, et al. Sex and gender in cardiovascular medicine: presentation and outcomes of acute coronary syndrome. Eur Heart J. 2020;41(13):1328-36. https://doi.org/10.1 093/eurheartj/ehz898.

27. Collins C, Landivar LC, Ruppanner L, Scarborough WJ. COVID-19 and the gender gap in work hours. Gend Work Organ. 2020;28(S1):101-12. https:// doi.org/10.1111/gwao.12506.

28. Landivar LC, Ruppanner L, Scarborough WJ, Collins C. Early signs indicate that COVID-19 is exacerbating gender inequality in the labor force. Socius. 2020;6:237802312094799. https://doi.org/10.1177/2378023120947997.

29. Morgan R, George A, Ssali S, Hawkins K, Molyneux S, Theobald S. How to do (or not to do) ... gender analysis in health systems research. Health Policy Plan. 2016;31 (8):1069-78. https://doi.org/10.1093/heapol/czw037.

30. Frenz P, Delgado I, Kaufman JS, Harper S. Achieving effective universal health coverage with equity: evidence from Chile. Health Policy Plan. 2014; 29(6):717-31. https://doi.org/10.1093/heapol/czt054.

31. Vega J, Bedregal P, Jadue L, Delgado I. Equidad de género en el acceso a la atención de salud en Chile [gender inequity in the access to health care in Chile]. Rev Med Chil. 2003 Jun;131(6):669-78. https://doi.org/10.4067/S003498872003000600012

32. Nazzal C, Alonso F. Younger women have a higher risk of in-hospital mortality due to acute myocardial infarction in Chile. Rev Esp Cardiol. 2013; 66(2):104-9. https://doi.org/10.1016/j.recesp.2012.07.015.

33. Springer KW, Mager Stellman J, Jordan-Young RM. Beyond a catalogue of differences: a theoretical frame and good practice guidelines for researching sex/gender in human health. Soc Sci Med. 2012;74(11):1817-24. https://doi.org/10.1016/j.socscimed.2011.05.033.

34. Levesque JF, Harris MF, Russell G. Patient-centred access to health care: conceptualising access at the interface of health systems and populations. Int J Equity Health. 2013;12(1):18. https://doi.org/10.1186/1475-9276-12-18.

35. Propp DA, Krubert C, Sasson A. Healthcare economics for the emergency physician. Am J Emerg Med. 2003;21(1):55-60. https://doi.org/10.1053/a jem.2003.50024.

36. Xiao H, Augusto O, Wagenaar BH. Reflection on modern methods: a common error in the segmented regression parameterization of interrupted time-series analyses. Int J Epidemiol. 2020;50(3):1011-5. https://doi.org/10.1 093/ije/dyaa148.

37. Merkler AE, Parikh NS, Mir S, Gupta A, Kamel H, Lin E, et al. Risk of ischemic stroke in patients with coronavirus disease 2019 (COVID-19) vs patients with influenza. JAMA Neurol. 2020;77(11):1366. https://doi.org/10.1001/jama neurol.2020.2730,

38. Long B, Brady WJ, Koyfman A, Gottlieb M. Cardiovascular complications in COVID-19. Am J Emerg Med. 2020;38(7):1504-7. https://doi.org/10.1016/j.a jem.2020.04.048.

39. Abate BB, Kassie AM, Kassaw MW, Aragie TG, Masresha SA. Sex difference in coronavirus disease (COVID-19): a systematic review and meta-analysis. BMJ Open. 2020;10(10):e040129. https://doi.org/10.1136/bmjopen-2020-040129.

40. Cerda AA, García LY. Factors explaining the fear of being infected with COVID-19. Health Expect. 2021;00:1-7. https://doi.org/10.1111/hex.13274.

41. Chmielewska B, Barratt I, Townsend R, Kalafat E, Meulen J, Gurol-Urganci I, et al. Effects of the COVID-19 pandemic on maternal and perinatal outcomes: a systematic review and meta-analysis. Lancet Glob Health. 2021 Jun;9(6):e759-72. https://doi.org/10.1016/S2214-109X(21)00079-6.

42. Cousins S. COVID-19 has "devastating" effect on women and girls. Lancet. 2020;396(10247):301-2. https://doi.org/10.1016/S0140-6736(20)31679-2.

\section{Publisher's Note}

Springer Nature remains neutral with regard to jurisdictional claims in published maps and institutional affiliations. 